\title{
O professor e o processo ensino-aprendizagem: um estudo com os docentes do curso de ciências contábeis da UNEMAT-Cáceres
}

\author{
Pâmela Gabriela Ramos \\ Universidade do Estado de Mato Grosso \\ Brasil \\ Edivander Hurtado Couto \\ Faculdade do Pantanal - Fapan \\ Denise Pereira Pacheco \\ Universidade do Estado de Mato Grosso \\ Joana Pessoa Avelino Forte \\ Centro Federal de Educação Tecnológica de Minas Gerais (CEFET-MG)
}

Data da submissão: 19/02/2018

Data de aceite: 20/02/2019

\section{RESUMO}

O curso superior de Ciências Contábeis, regulamentado pela Resolução $\mathrm{n}^{\circ} 10$ do Conselho Nacional de Educação (CNE), Câmara de Educação Superior (CES) e a Lei de Diretrizes Básicas (LDB) tem maior necessidade de combinar teorias e práticas no processo ensinoaprendizagem, desta forma, Mizukami (1986) afirma que há diferentes formas de se conceber o fenômeno educativo, cabendo ao docente escolher e adaptá-las da melhor forma possível. A pesquisa teve como objetivo elencar as dificuldades de aprendizagem apresentadas pelos acadêmicos do curso de Ciências Contábeis da Universidade do Estado de Mato Grosso (Unemat) sob a visão dos professores e identificar quais os métodos adotados para redução do problema. Trata-se de uma pesquisa qualitativa-quantitativa, cuja coleta de dados ocorreu por meio da aplicação de um questionário semiestruturado. Os dados mensuráveis foram tabulados através do Excel e as evocações organizadas através da análise de conteúdo com auxilio do software Atlas Ti. Os professores pesquisados apontam que os estudantes apresentam dificuldades e para reduzir/eliminar esses fatores, os professores indicam leituras complementares, verificação de que o problema não está na forma de condução das aulas, adoção de meios mais simples de abordagem do tema e explicar novamente o conteúdo. Quando questionados sobre o que pode ser feito, predominou a implantação de projetos, estímulos e melhorias dos recursos didáticos. Percebe-se assim o papel da Universidade em fornecer subsídios e estímulos ao processo ensino-aprendizagem, cita-se a formação continuada, a semana pedagógica e as inúmeras outras possibilidades que propiciem a evolução do processo ensino-aprendizagem no ensino superior.

PALAVRAS-CHAVE: Professor, Ensino Superior, Dificuldades e Ensino-Aprendizagem. 


\section{INTRODUÇÃO}

O atual contexto profissional exige dos indivíduos formação em curso superior, porém pouco se debate sobre a qualidade do ensino oferecido nas instituições públicas e privadas e um dos pontos mais importantes a ser considerado na educação refere-se, sem dúvida as metodologias de ensino nos cursos de graduação. A prática no ensino da contabilidade faz parte de uma realidade ainda ausente no ensino superior. (LAFFIN, 2005). As lacunas existentes na avaliação do ensino-aprendizagem podem ser preenchidas através de professores qualificados e aptos a identificar as dificuldades encontradas neste processo, universidade bem estruturada, metodologias adequadas e educação continuada para abordagem e reciclagem de temas pertinentes a aprendizagem.

As dificuldades de aprendizagem dos discentes não ocorrem somente na faculdade, vindo esta desde os primeiros anos de escola e se alongam no decorrer de toda a vida trajetória escolar até chegar à universidade. Como no ensino fundamental e médio essas dificuldades não foram cessadas a incidência é que se repita ao longo da graduação. Capacitar e formar as pessoas em um curso para que se tornem profissionais aptos para o exercício da profissão com qualidade, além da detecção do que dificulta o processo de aprendizagem dos estudantes é responsabilidade e um dever da instituição bem como do professor como um todo. Diante do exposto surge a problemática: Quais as dificuldades de aprendizagem apresentadas pelos alunos na visão dos professores do Curso de Ciências Contábeis da Universidade do Estado de Mato Grosso (Unemat) - Campus de Cáceres?

Partindo dos pressupostos acima, a pesquisa apresenta como objetivo geral: Identificar as ações dos professores do departamento de Ciências Contábeis da Unemat - Cáceres para reduzir as dificuldades dos acadêmicos no processo de ensino-aprendizagem.

Esse estudo limita-se as metodologias de ensino utilizadas pelos professores do Curso de Ciências Contábeis da Unemat - Cáceres para reduzir as dificuldades dos acadêmicos no processo de ensino-aprendizagem. Não é foco da pesquisa as metodologias de ensino utilizados pelos professores dos demais cursos da Unemat.

\section{O ENSINO DA CONTABILIDADE}

Atualmente, o ensino de contabilidade procura atender a um conjunto de requisitos, dentre eles: as perspectivas do acadêmico, as diversas abordagens de atuação profissional; revelar a capacidade e competência profissional do estudante em face das demandas do mercado de trabalho e do crescimento econômico do país; estimular a discussão acerca dos assuntos que envolvem a harmonização e padrões internacionais de contabilidade e demais órgãos internacionais; formar profissionais conscientes do seu papel na sociedade e que preservem a ética nas atividades contábeis, bem como profissionais que desempenhem seu trabalho com vistas a promover a integração social, econômica e sustentável das regiões onde atuam (BRASIL, 1996; BRASIL CNE/CES 10/04).

Peleias et al (2007) relata que o ensino da contabilidade no Brasil teve início com as aulas de Ciências Econômicas em 1808. Neste ano foi criada no Rio de Janeiro uma cadeira de "economia política", em 1809 essa cadeira passou a ser denominada Aula de Comércio, sendo este considerado o embrião do ensino comercial no Brasil, hoje Curso de Ciências Contábeis.

Desde os primórdios do ensino do que viria a ser a contabilidade, havia uma preocupação com a seleção de docentes qualificados, Candiotto e Blanck (2009, p. 95) relatam que:

Os professores que ministravam a Aula de Comércio eram chamados de lentes e o Governo Imperial tinha uma grande preocupação com a lisura com que esses docentes eram nomeados. Prova disso é que em 31 de janeiro de 1842, o Governo 
Imperial definiu com o Decreto $\mathrm{n}^{\circ} .121$, os critérios que deveriam ser adotados para a seleção de docentes.

Conforme Santos (2006), a responsabilidade para abordar a contabilidade no Brasil foi da Escola de Comercio Álvares Penteado, fundada em 1902 que funcionava com a missão que há um século lhe foi outorgada pelos fundadores: formar profissionais com excelência de ensino, sendo a mesma responsável pela formação de alguns professores de destaque nessa época como Francisco D’Auria e Frederico Herrmann Jr.

Candiotto e Blanck (2009) relatam que em 1908, a Escola Álvares Penteado criou o curso superior de Ciências Comerciais com formação geral de quatro anos, que concedia o diploma de contador. As disciplinas eram estabelecidas através de um decreto e abordavam as seguintes temáticas; Contabilidade, Contabilidade Mercantil, Contabilidade Agrícola e Industrial e Contabilidade Pública.

Conforme Oliveira (2010), em 1945, por meio do decreto-lei $\mathrm{n}^{\circ} 7.988$, foi instituído o curso superior de Ciências Contábeis e Atuariais, habilitado à formação e titulação de bacharéis em Ciências Contábeis, com duração de 4 (quatro) anos. No ano de 1946 a contabilidade se fortaleceu e foi criada a faculdade de Ciências Contábeis Econômicas e administrativas de São Paulo.

A contabilidade no Brasil teve grande desenvolvimento por volta dos anos 60 , conforme Santos (2006, p.15):

[...] foi criada a Faculdade Ciências Econômicas e Administrativas da Universidade de São Paulo. O professor José da Costa Boucinhas introduziu um novo método de ensino o norte-americano, com importantes adaptações a realidade Brasileira. Como consequências desse trabalho surge em 1971, o livro de contabilidade Introdutória por uma equipe de professores do departamento de Ciências Contábeis e Atuariais da Faculdade de Ciências Econômicas e Administrativas da Universidade de São Paulo. Livro esse que passou a ser adotado em todas as faculdades do Brasil.

Atualmente o curso de Ciências Contábeis é regulamentado pela Resolução $\mathrm{n}^{\circ} 10$ do Conselho Nacional de Educação (CNE), Câmara de Educação Superior (CES), a qual "Institui as Diretrizes Curriculares Nacionais para o Curso de Graduação em Ciências Contábeis, bacharelado, e dá outras providências."

No Brasil, além das exigências do mercado de trabalho, a formação do profissional em contabilidade é acompanhada por diversas regras normativas, dentre elas a Lei 9.394, de 20 de dezembro de 1996 - LDB, que estabelece as diretrizes e bases da educação nacional (BRASIL, 1996). Esta Lei também estabelece "os níveis escolares e as modalidades de educação e ensino, bem como suas respectivas finalidades" (SOARES, 2002).

As regras estabelecidas contribuem para a formação de mão de obra qualificada, de profissionais adaptáveis a novas demandas e exigências assim como para a promoção de sólida formação profissional, iniciando-se por meio de projeto pedagógico nas universidades e por currículos flexíveis das instituições de ensino.

A Resolução CNE/CES 10, de 16 de dezembro de 2004, instituiu as diretrizes curriculares dos cursos de graduação em Ciências Contábeis, em nível de bacharelado, como forma de atender às exigências do mercado de trabalho e às regras formais do ensino superior. Dentre as exigências dessa Resolução, as Instituições de Ensino Superior (IES) devem organizar seu currículo voltado para a formação de profissionais com perfis de competências e habilidades.

Quanto à capacitação do futuro contador, o art. $3^{\circ}$ da Resolução CNE/CES No 10/2004 estabelece que o curso de graduação em Ciências Contábeis deve proporcionar meios para que ele possa: (i) compreender as questões científicas, técnicas, sociais, econômicas e financeiras, em âmbito nacional e internacional e nos diferentes modelos de organização; (ii) apresentar 
pleno domínio das responsabilidades funcionais envolvendo apurações, auditorias, perícias, arbitragens, noções de atividades atuariais e de quantificações de informações financeiras, patrimoniais e governamentais, com a plena utilização de inovações tecnológicas; (BRASIL, CNE/CES 10/04).

Tal Resolução contempla e contextualiza a formação, as habilidades requeridas e o campo de atuação profissional. Portanto, cabe aos agentes de ensino promover meios para atender às necessidades do aluno e da comunidade, adaptando suas grades curriculares e métodos de abordagem em sala de aula na formação do profissional capaz de cumprir as exigências do mercado e suas próprias perspectivas.

Para Marion e Marion (2008), a metodologia para se transmitir aos alunos os conhecimentos devem estar constantemente em avaliação pelo professor. Os cursos superiores de Ciências contábeis tem maior necessidade de combinar teorias e praticas. Segundo Laffin (2005), em pesquisa com professores, estes dizem relacionar a teoria e prática quando aplicam as técnicas de escrituração, quando utilizam ferramentas contábeis, exercícios propostos, estudos de caso, processos interativos, trabalhos em equipe entre outras modalidades de ensino.

Laffin (2005) diz que os professores avaliam o processo de aprendizagem por parte dos alunos através de provas e trabalhos. Os meios de avaliar são utilizados para avaliar se o aluno sabe da disciplina ou se ele entende da mesma, estando aptos para o exercício da profissão. Porém os resultados desses tipos de avaliações indicam índices regulares de aprendizado. Para Mizukami (1986), há diferentes formas de se conceber o fenômeno educativo, cabendo ao docente escolher e adaptá-las da melhor forma possível, contribuindo para a relação ensino-aprendizagem do estudante.

\subsection{O CURSO DE CIÊNCIAS CONTÁBEIS NA UNEMAT}

O curso de Ciências Contábeis da Universidade do Estado de Mato Grosso - Campus Cáceres teve início em 1995. Atualmente conta com 80 vagas anuais, o curso é semestral com turmas de período matutino. Nos últimos anos, a relação do número de candidatos por vaga variou entre 10 e 12 candidatos. $O$ curso tem duração mínima de 04 anos e integralização máxima de 06 anos, com carga horária total de 3 mil horas.

O currículo do curso segue a Resolução MEC/CNE no 10/2004 e proporciona a formação de conhecimentos exigidos pela sociedade contemporânea. A organização didáticopedagógica do curso segue Resolução no 42/2007 CEPE, que fixou o Currículo Pleno do Curso de Ciências Contábeis, do Setor de Ciências Sociais Aplicadas.

As avaliações que medem o ensino e a aprendizagem seguem os padrões normatizados pela Resolução no 37/1997- CEPE, Cap. X, arts. 92 a 109, que define que a média numérica exigida para aprovação é 70, ou seja, $70 \%$ de acertos no conjunto de avaliações do período e $75 \%$ de presenças nas aulas durante o curso. Caso a média não seja alcançada, a Resolução propõe exame final aos que obtiverem média numérica de 40 , ou $40 \%$ de acertos no conjunto de avaliações do período, e uma nova média é obtida, de 50, que se refere à média das avaliações do período e à média do exame. Cada aula tem 50 minutos de duração.

O Curso de Ciências Contábeis do Campus Universitário de Cáceres, criado pelo Decreto $n^{\circ}$ 196/95, do Conselho Estadual de Educação do Estado do Mato Grosso foi reconhecido pela Portaria no 291/03 - C. E.E, Cujo Projeto Político Pedagógico (PPP), tem como: 
Preparar os acadêmicos para uma atividade profissional, que tem por finalidades: o registro dos fatos contábeis, os atos de planejamento e controle do patrimônio das organizações, e, a pesquisa para o desenvolvimento da Ciência Contábil, bem como atuação na docência do Magistério Superior.

\title{
OBJETIVO GERAL
}

Formação de profissionais com conhecimentos multidisciplinares, capacitados e qualificados ao exercício profissionais, dotados de senso analítico e crítico, em consonância com os valores éticos, com visão ampla e abrangente e com conhecimentos específicos em Contabilidade Geral, Gerencial, Pública e Social.

\section{OBJETIVO ESPECÍFICO}

\begin{abstract}
- Formar profissionais em Ciências Contábeis que exerçam com ética e proficiência as atribuições que lhes são prescritas através de legislação específica, uma vez que a formação do contador pressupõe o oferecimento de capacitação cientifica e instrumental e, ao mesmo tempo, o desenvolvimento de uma percepção critica da realidade.

- Estimular o acadêmico a buscar o auto desenvolvimento, como base de sua realização profissional.

- Proporcionar o conhecimento de conteúdos fundamentais da teoria e prática contábeis, permitindo uma visão crítica das organizações, da sociedade e da profissão.

- Estimular a pesquisa na área contábil, visando difundir o desenvolvimento e aperfeiçoamento de suas teorias e técnicas.

- Capacitar para a compreensão e o processamento de informações econômicopatrimoniais para a elaboração, análise e interpretação de demonstrações e relatórios contábeis, visando o controle patrimonial e a tomada de decisões.

- Preparar profissionais com competência e habilidades para atuar nas áreas: geral, gerencial, pública e social (rural e ambiental).
\end{abstract}

O plano em parte citado visa nortear o ensino da contabilidade na instituição, proporcionando conhecimento teórico e prático, contribuindo para a formação de profissionais aptos a exercer todo e qualquer tipo de atividade relacionado com a contabilidade.

\subsection{AS DIFICULDADES DE APRENDIZAGEM NO ENSINO SUPERIOR}

O professor é o profissional, quer pelas experiências em sala de aula, quer pelo contato mais próximo ao aluno, é considerado o mais habilitado para detecção dos problemas envolvendo as dificuldades de aprendizagem. Através da sua experiência como docente e de sua observação, o professor poderá detectar quem realmente está com dificuldade de aprendizagem, diagnosticando até mesmo as causas destas.

Conforme Laffin (2005), os professores ao detectar as causas de dificuldades de aprendizagem, relacionam-nas por sua vez com diversos fatores, citando a relação familiar, a formação no $1^{\circ}$ e $2^{\circ}$ grau e as diferentes ementas pedagógicas, há também a uma parcela considerável dos alunos que precisam trabalhar e acaba por diminuir a disponibilidade para o estudo e a própria forma de administrar a sua base formativa.

Quintana (2006) diz que, um dos pontos mais importantes a ser considerado na educação refere-se, sem dúvida, ás práticas de aprendizagem em curso superior. O aluno ao entrar na graduação, por diversas vezes, traz as marcas, positivas ou negativas das experiências anteriores (ensino fundamental e médio), impactando de início suas concepções a cerca das formas de ensino-aprendizagem do ensino superior. Conforme Laffin (2005, p. 203): 
O processo de ensino-aprendizagem ocorre quando o sujeito nele envolvido são capazes de tornar presentes objetos ausentes para a correlação das experiências vivenciadas, esse processo ensino-aprendizagem significa quando juntos ,professor e aluno, são capazes de revisitar o já presente e torná-lo ainda mais abrangente na emancipação de ambos.

Filho (2010) ressalta outro problema recorrente inerente às dificuldades no processo de ensino, muitos estudantes precisam conciliar estudo, trabalho e lazer, e ainda aquelas dificuldades oriundas da metodologia adotada em sala de aula e do processo de ensino do curso de Ciências Contábeis, nem sempre alinhados com os propósitos do curso e as perspectivas dos alunos, causando desmotivação ao estudante.

A cerca da percepção dos professores no que se refere a avaliação das dificuldades de ensino e aprendizagem, Luckesi (2000, p. 06) afirma que:

Para qualificar a aprendizagem de nossos educandos, importa, de um lado, ter clara a teoria que utilizamos como suporte de nossa prática pedagógica e, de outro, o planejamento de ensino que estabelecemos como guia para a nossa prática de ensinar no decorrer das unidades de ensino do ano letivo.

Para definir o grau de qualidade do ensino superior, é necessário um diagnóstico preciso e detalhado da atual situação das Universidades brasileiras, observando a contextualização social e regional de cada instituição, para possibilitar a definição de políticas educacionais e de gestão administrativas específicas.

\section{RESULTADOS}

Conhecer o contexto na qual se desenvolve o processo ensino-aprendizagem, inclusive o perfil e os profissional envolvidos é de suma importância para identificar as falhas e as possíveis alternativas e melhorias a serem implantas para diminuir os conflitos envolvendo as dificuldades de aprendizado apresentadas pelos estudantes do ensino superior.

Ressalta-se que o objeto da pesquisa é o curso de Ciências Contábeis da Unemat campus Cáceres, que atualmente conta 298 alunos, cujo turno de funcionamento é o matutino, onde já se formaram 35 turmas, totalizando mais de 700 profissionais até o ano de 2015.

Visando atender o objetivo geral da pesquisa, foi aplicado um questionário entre os dias 15 e 18 de setembro de 2015, contendo 19 questões, abertas e fechadas. A primeira parte refere-se ao perfil dos docentes da Instituição.

No que se refere à graduação cursada pelo professor, dos 19 (dezenove) participantes da pesquisa, 11 (onze) profissionais tem formação acadêmica no curso de Ciências Contábeis, 8 (oito) com formação diversa na qual se encontram Letras, Matemática, Computação, Ciências Econômicas, Direito e Administração. Ressalta-se que 2 (dois) professores tem formação em dois cursos, na qual repetidamente aparece a faculdade de Direito.

Gráfico 01: Área de graduação? 


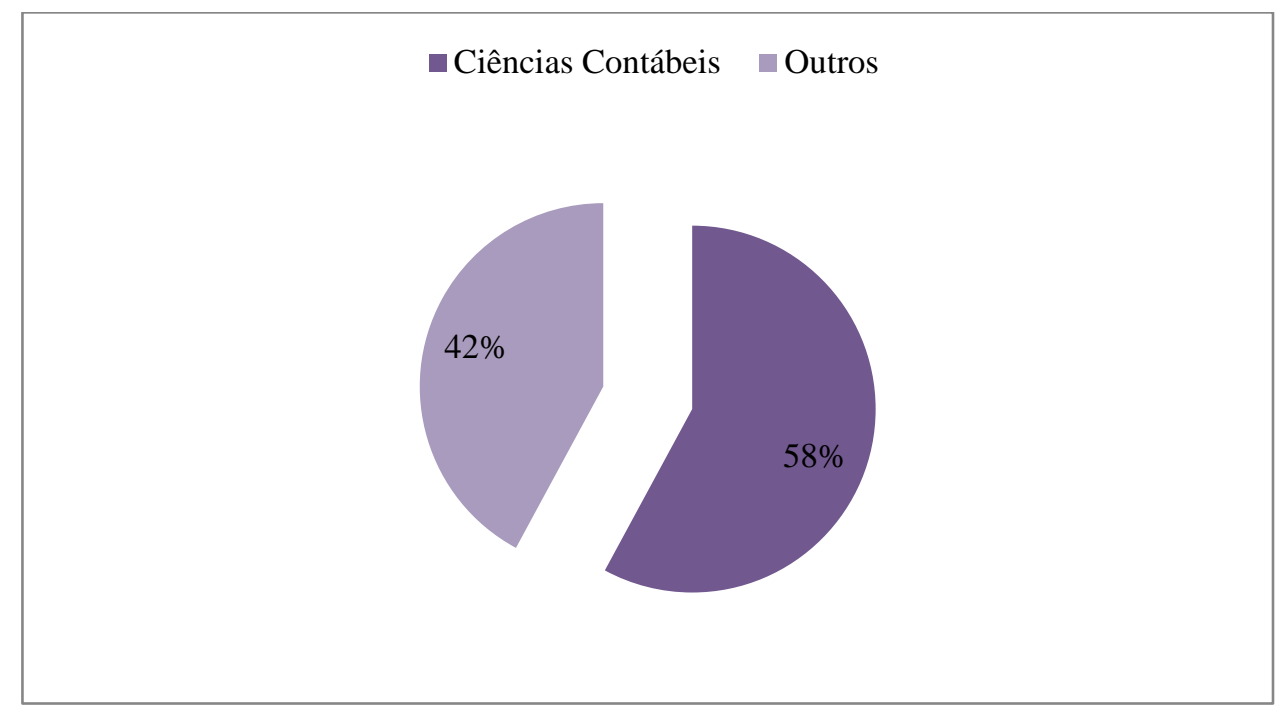

Fonte: Dados da Pesquisa. 2015.

Quando questionado o estabelecimento em qual se formou, constatou-se que a maioria advém da Unemat aparecendo também a Universidade Federal de Mato Grosso, Universidade Rural do Rio de Janeiro, Universidade Dom Bosco/RS, Faculdade Adventista de Administração/SP e Universidade de Santa Maria (RS), sendo as 3 (três) últimas Instituições de Ensino Superior Privada.

Gráfico 02: Instituição de Origem

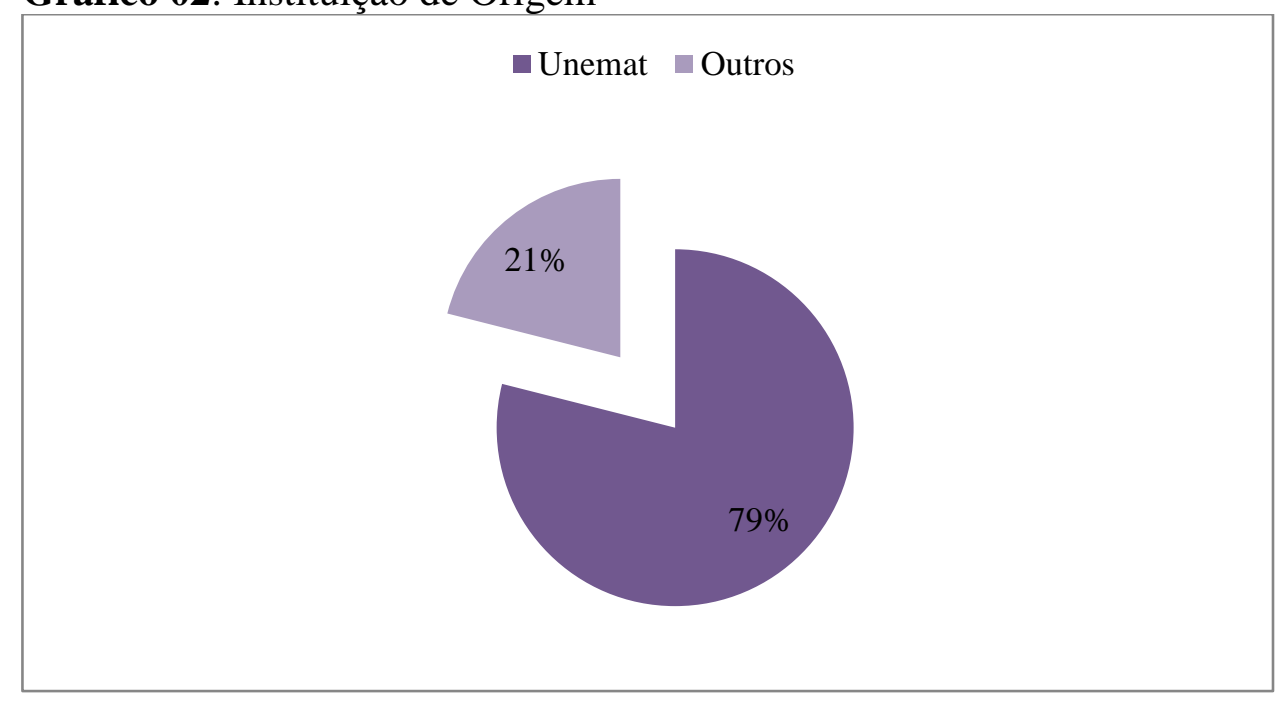

Fonte: Dados da Pesquisa, 2015.

Luz (2012) ressalta que atualmente a experiência e o aprendizado obtidos nos bancos das universidades já não são mais suficientes para garantir o posicionamento dos profissionais, com isso, um curso de pós-graduação pode ser uma alternativa eficaz.

A valorização e qualificação dos professores são consideradas fundamentais para a melhoria da qualidade da educação. É de fundamental importância estabelecer vínculos entre os resultados das avaliações de aprendizagem e a formação dos professores, tanto a inicial 
como a educação continuada, a fim de que o processo de aprendizagem em sala de aula possa ser efetivamente renovado. UNESCO (2014).

No que se refere ao grau de formação dos professores do curso de Ciências Contábeis verificou-se que 2 (dois) entrevistados são graduados, 6 (seis) pós-graduado, 7 (sete) Mestres e 3 (três) Doutores, sendo as qualificações em diversas áreas do conhecimento como: Contabilidade, Gestão na área de educação, Administração, Sociologia dentre outros.

Gráfico 03: Grau de Escolaridade

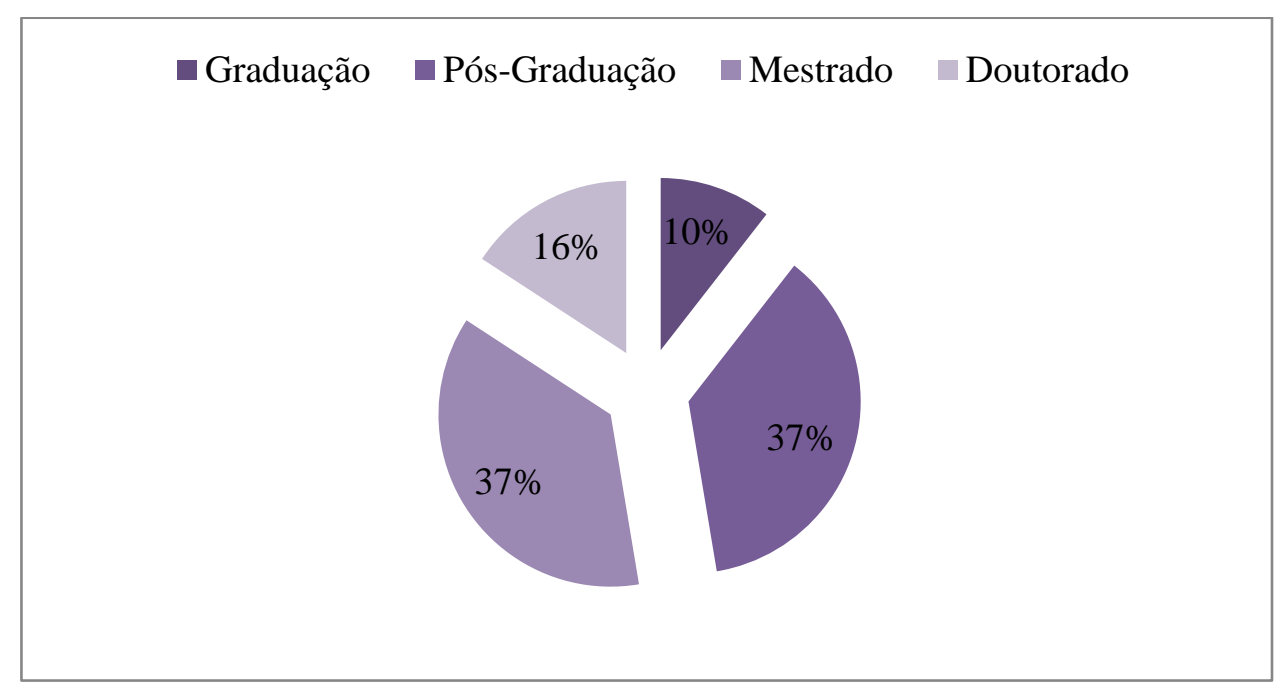

Fonte: Dados da Pesquisa, 2015.

Adentrando no quesito específico com relação ao exercício da profissão, buscou-se saber a relação de trabalho estabelecida com a Unemat, sendo que dentre os entrevistados 10 (dez) são contratados e 9 (nove) efetivos.

Gráfico 04: Vínculo com a Unemat

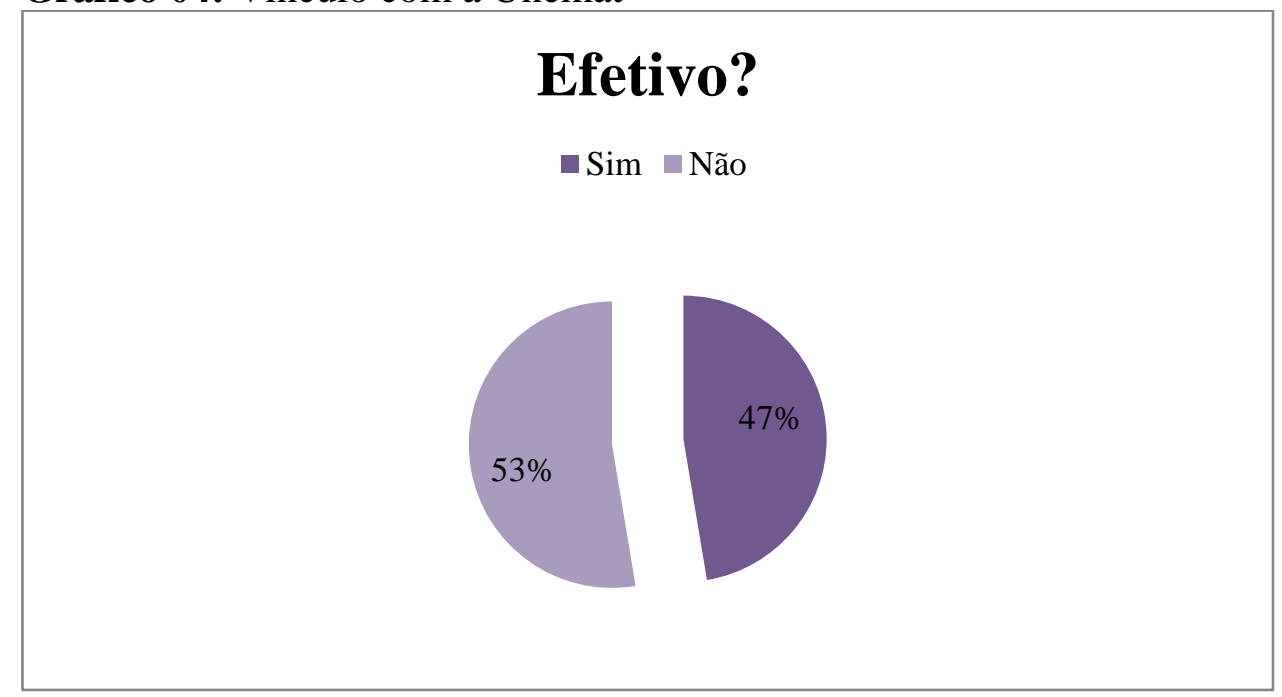

Fonte: Dados da Pesquisa, 2015.

Com relação ao tempo de atuação do professor, Barros (2012), diz que há uma relação entre a experiência do professor e aprendizado dos alunos, a experiência permite que o professor aprenda a ensinar melhor no ano seguinte o que ensinou no ano anterior.

Com relação aos professores atuantes na Unemat, a pesquisa apontou variação no tempo de atuação, onde os intervalos de 1 a 5 e 06 a 10 anos apresentam o mesmo percentual, 
sendo o menor tempo de profissão 3 (três) meses e o maior 35 (trinta e cinco) anos como professor. A maior incidência de atuação na Unemat está no primeiro intervalo de tempo.

Gráfico 05: Há quanto tempo leciona?

$\square 0$ a 5 anos $\square 06$ a 10 anos $\square 11$ a 20 anos $\square 21$ a 30 anos $\square$ acima 30 anos

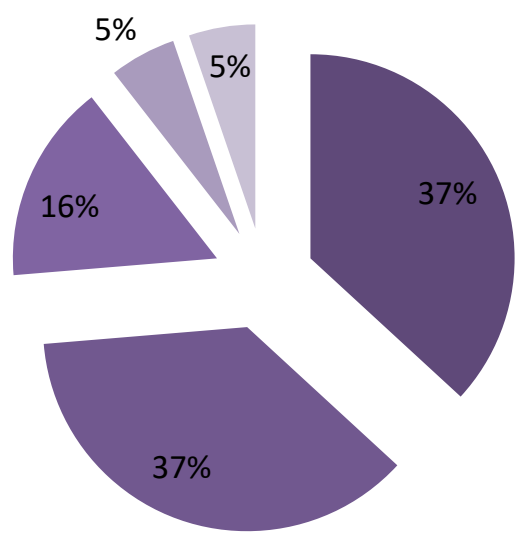

Fonte: Dados da Pesquisa, 2015.

Gráfico 06: Há quanto tempo leciona na Unemat?

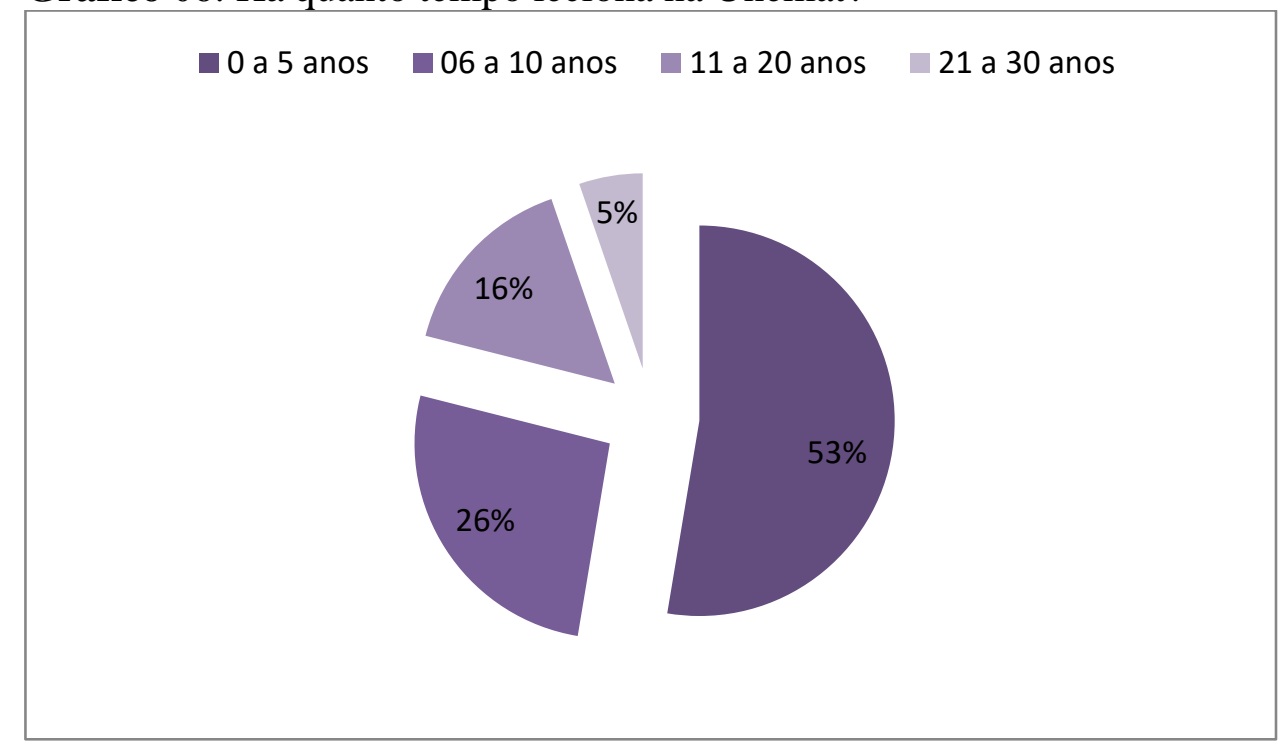

Fonte: Dados da Pesquisa, 2015.

Esta fase está relacionada a atuação do professor e sua percepção referentes as dificuldades apresentadas pelos estudantes dentro da disciplina que lecionam, ressaltando que 
a maioria dos entrevistados estão lecionando 3 disciplinas, sendo que na maioria dos casos a mesma está voltada para sua área de formação.

Com relação a percepção que o professor tem a cerca das dificuldades de aprendizagem dos alunos, a maioria afirma que observam que os alunos apresentam efetivamente alguma dificuldade em aprender e/ou assimilar o conteúdo abordado.

Gráfico 07: Observa dificuldade no aprendizado dos acadêmicos?

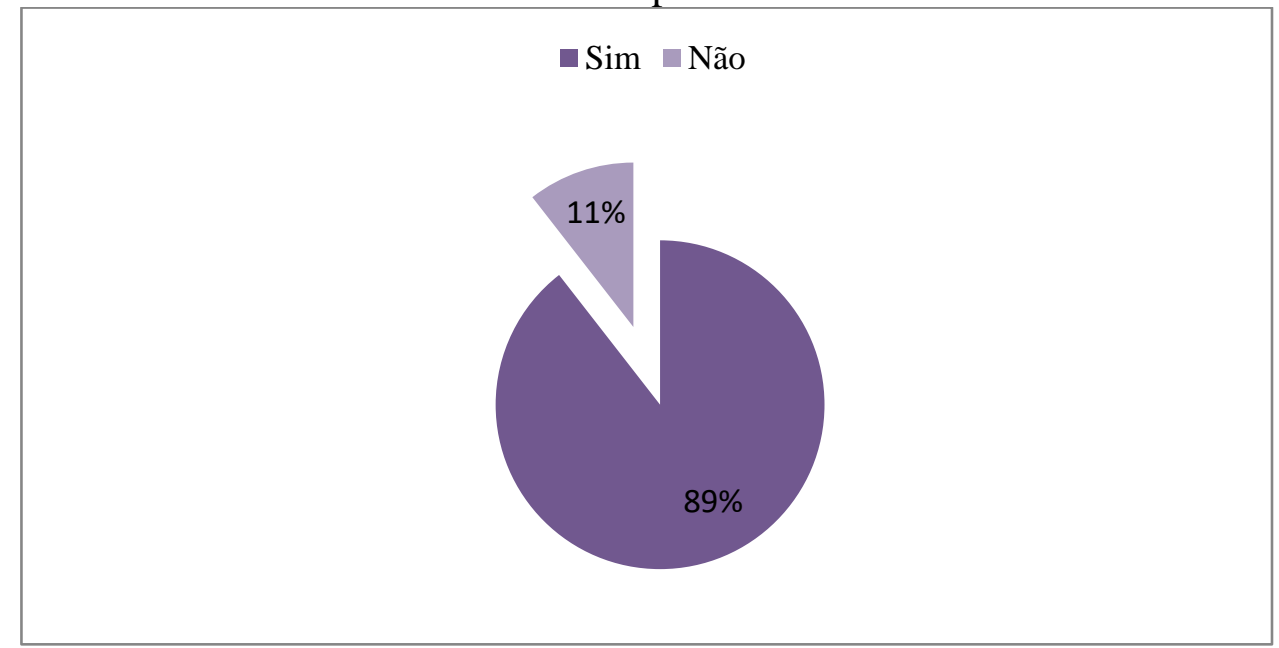

Fonte: Dados da Pesquisa, 2015.

O relato das dificuldades apresentadas pelos alunos na percepção do professor foi analisado através da análise de conteúdo com auxílio do software Atlas TI. Dentro contexto, as dificuldades mais citadas foram o baixo conhecimento, falta de interesse, dificuldades de assimilar conteúdo abordado e por último o despreparo consequência do ensino básico. Cabe lembrar que dentre as falas, as dificuldades encontram-se diretamente associadas a interpretação, raciocínio e assimilação do assunto.

Stallivieri (2006) ressalta que as dificuldades apresentadas são oriundas do despreparo dos alunos, que chegam ao ensino superior com deficiências do ensino fundamental. Silva et al (2012), em uma pesquisa referente as dificuldades de produção de textos por estudantes do ensino superior, afirma que estes possuem dificuldades tanto no ato de ler quanto no ato de escrever.

Figura 01: Temáticas das dificuldades apresentadas na fala dos entrevistados.

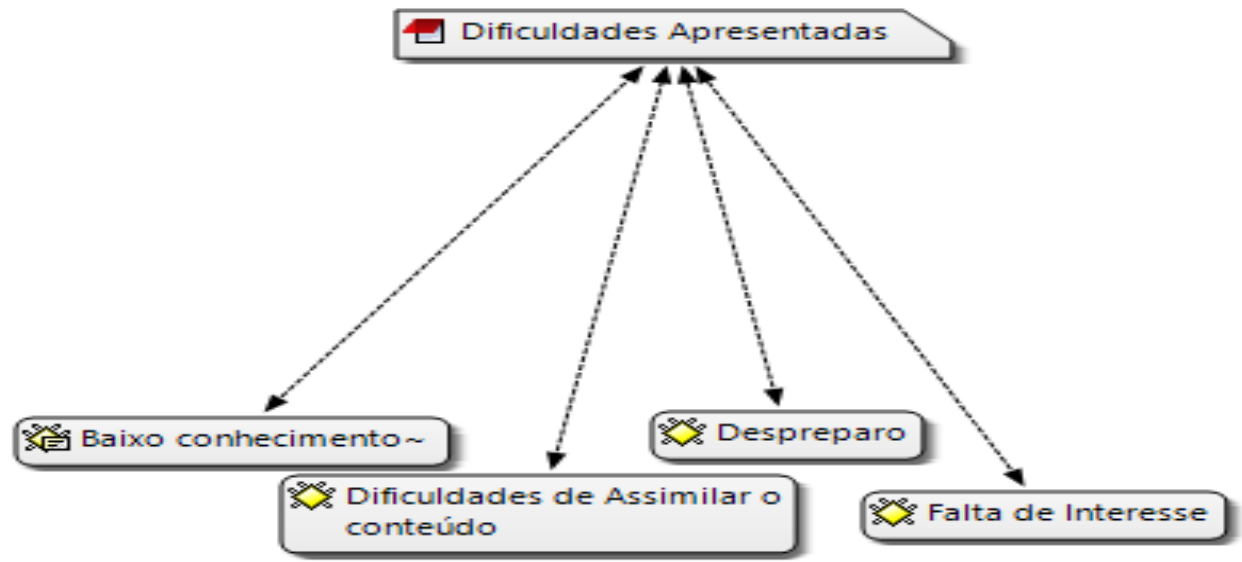

Fonte: Dados da Pesquisa, 2015 
Quando questionados sobre a qual fato pode ser atribuído a dificuldade dos acadêmicos, as respostas foram praticamente unânimes, onde repetidamente apareceu o fator falta de leitura associado a dificuldades de intepretação e vocabulário restrito. Nesse contexto Martins (2007) afirma que a leitura seria a ponte para o processo educacional eficiente, proporcionando a formação integral do indivíduo.

Outro ponto de grande relevância é com relação a melhor organização e atualização da grade curricular do curso, cabe apresentar a integra da fala de um docente: "Não há disciplinas que embasam a aplicabilidade da Contabilidade Pública, tais como Direito Financeiro e Noções de Direito Administrativo e Constitucional, o que gera uma dificuldade natural em razão dessas lacunas."

Visando conhecer o nível de preparo dos docentes em relação a como reduzir as dificuldades de aprendizagem dos acadêmicos,, percebe-se que a maioria em algum momento teve uma qualificação específica para o exercício da função.

Gráfico 08: Teve algum treinamento?

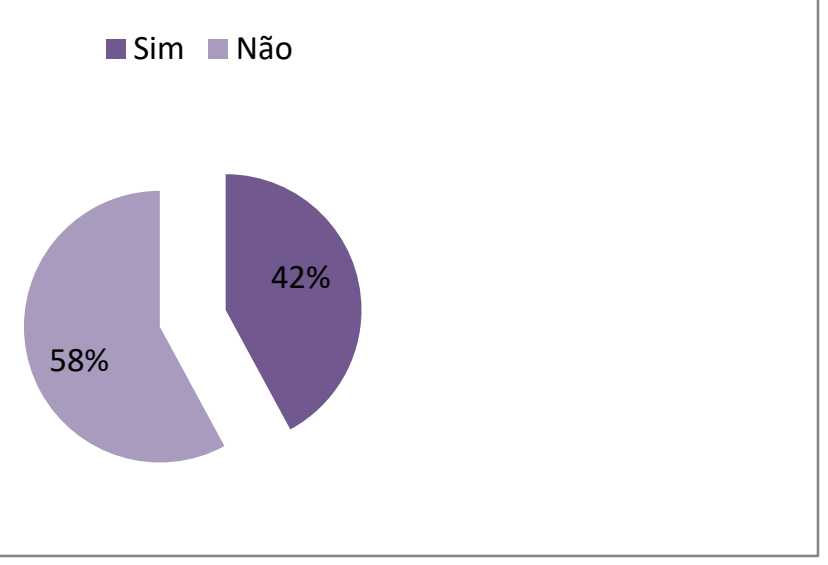

Fonte: Dados da Pesquisa, 2015.

Ainda nesse contexto, importante ressaltar que a Semana Pedagógica e o Mestrado foram os lugares onde houve a qualificação, cita-se ainda outras Instituições de Ensino Superior e o aprendizado obtido durante a graduação, a seguir a fala do entrevistado: "Treinamento não, mas como meu curso foi licenciatura, tenho um conhecimento a mais do que somente se fosse bacharelado."

A pergunta chave da pesquisa pode ser resumida da seguinte forma: qual sua atitude quando percebe que um acadêmico apresenta alguma dificuldade de aprendizado? As respostas mais expressivas estão ligadas a perguntas visando identificar déficit de aprendizagem, indicação de leituras complementares, verificação de que o problema não está no docente, adoção de métodos mais simples de abordagem do tema e explicar novamente o conteúdo, sendo que neste último item houve uma ressalva: "Devido o tempo e a carga horária da disciplina, voltar o conteúdo não se pode fazer com tanta frequência". Cita-se ainda o caso de um docente que marca aulas extras independente do horário fixado pela instituição.

Por último adentrou-se em um ponto mais específico; a proposta do que pode ser feito para reduzir os problemas de aprendizagem no ensino superior. Quando questionado sobre o que pode ser melhorado para auxiliar no aprendizado dos alunos do curso de Ciências Contábeis da Unemat, as opiniões dos profissionais foram equivalentes, sempre relacionadas a criação de projetos, em específico a bolsa monitoria para as disciplinas, estímulos aos estudantes (leituras, participações em eventos), recursos didáticos modernos e comprometimento do corpo docente.

Figura 02: Temáticas do que pode ser feito na fala dos pesquisados 


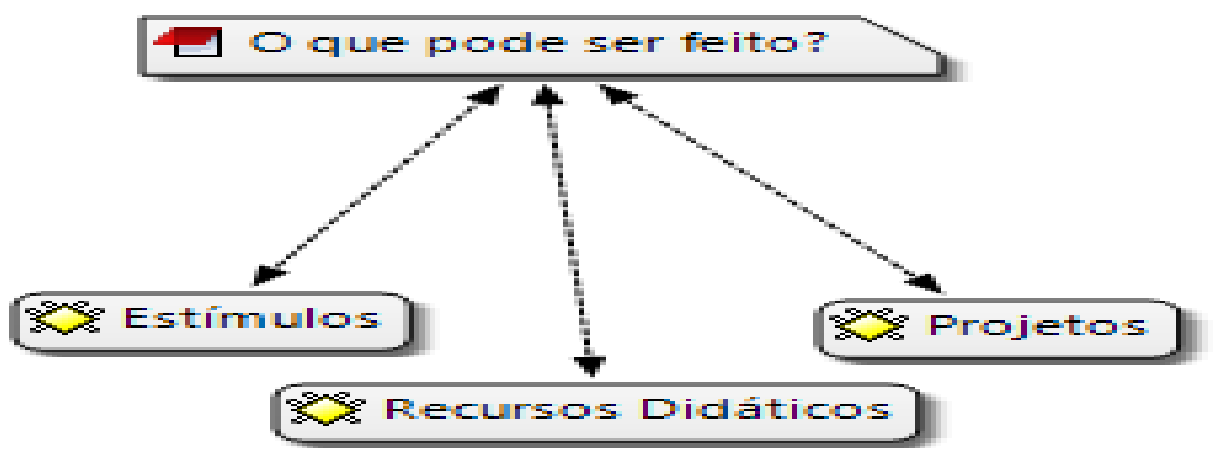

Fonte: Dados da Pesquisa, 2015.

No Brasil, a habilidade dos alunos vem ocupando papel central no debate de políticas públicas, vários estudos foram realizados referente ao que pode ser feito para melhorar a aprendizagem dos alunos, porém estão mais direcionadas aos estudantes do ensino médio e fundamental. Enfatizar o que pode ser feito para aprimorar a qualidade do ensino superior no Brasil será um grande passo para garantia de resultados (social e político) efetivos e duradouros.

\section{CONSIDERAÇÕES FINAIS}

Pouco se discute a cerca das dificuldades de aprendizagem apresentadas pelos estudantes do ensino superior. Identificar e analisar o contexto que contribui para os problemas de aprendizagem é de suma importância para o desenvolvimento de metodologias que possam reduzir as deficiências apresentadas no decorrer da graduação.

A pesquisa foi realizada visando responder os objetivos propostos, a primeira etapa foi a aplicação dos questionários aos docentes do curso de Ciências Contábeis, cujo objetivo foi conhecer o perfil dos professores atuantes no curso acima, sendo a maioria formado em Ciências Contábeis, oriundos da própria universidade, com formação além da graduação, com diversidade de tempo de atuação 3 meses e 35 anos, havendo equilíbrio nos vínculos de trabalho (contratado/efetivo).

O segundo momento refere-se à análise das principais causas de dificuldade de aprendizagem identificadas pelos professores que, na grande maioria responderam que os estudantes apresentam dificuldades, sendo estas relacionadas ao baixo interesse, dificuldades de assimilar o conteúdo e despreparo. Quando questionados sobre o que pode ser feito, predominou a implantação de projetos, estímulos e melhorias dos recursos didáticos.

A pesquisa é de fundamental relevância para que a partir dos achados, os docentes possam rever seu papel e estipular novos métodos e metodologias que auxiliem o processo ensino-aprendizagem. Pontua-se também o papel da Universidade em fornecer subsídios para os debates sobre a relação ensino-aprendizagem. Sugere-se a realização de estudos futuros com os estudantes, para que estes possam relatar as dificuldades que encontram ao ingressar na universidade e a percepção destes com relação ao que os professores podem fazer para reduzir este impacto e contribuir com a formação profissional dos acadêmicos.

\section{REFERÊNCIAS BIBLIOGRÁFICAS}


BRASIL, Lei $\mathrm{n}^{\circ}$ 9.394, de 20 de dezembro de 1996. Estabelece as diretrizes e bases da educação nacional. Diário Oficial [da] República Federativa do Brasil, Brasília, 23 dez. 1996.

BRASIL, Diretrizes Curriculares Nacionais do curso de graduação em Ciências Contábeis. PARECER CNE/CES N²69 DE 16 DE SETEMBRO DE 2004. Disponível em: portal.mec.gov.br/cne/arquivos/pdf/pces269_04.pdf. Acesso em 07 nov. 2014.

CANDIOTTO, Lucimara Bortoleto. MIGUEL, Maria Elisabeth. O curso de Ciências Contábeis na educação brasileira: das aulas de comércio ao curso superior de Ciências Contábeis (1808-1951). 2009.

FILHO, LAURINDO PANUCCI. Dificuldades e perspectivas dos estudantes de ciências contábeis da universidade federal do Paraná segundo o perfil sócio educacional. Dissertação, 2010.

LAFFIN, Marcos. De contador a professor: a trajetória da docência no ensino superior de contabilidade / Marcos Laffin - Florianópolis: [ s.n], 2005 ( Florianópolis. Impressão Universitária)

LUCKESI, Cipriano Carlos. O que é mesmo o ato de avaliar a aprendizagem? 2000.

LUZ. Márcia. A importância de uma pós-graduação na vida profissional. Disponível em: http://www.administradores.com.br/entrevistas/academico/a-importancia-de-uma-posgraduacao-na-vida-profissional/88/. Acesso em: 26 nov. 2014.

MARION, J. C.; MARION, M. M. C. Contabilidade Vista \& Revista, Vol. 11, N. 2, p. 3- 9, ago. 2008.

MARTINS, Maria Helena. O que é leitura? São Paulo: Brasiliense, 2007.

MIZUKAMI, Maria da Graça Nicoletti. Ensino: as abordagens do processo. São Paulo: EPU, 1986.OLIVEIRA. Elizabeth Castro Maurenza de A Gestão do Ensino da Contabilidade - Trajetória. ReFAE - Revista da Faculdade de Administração e Economia, v. 1, n. 2, p. 21-28, 2010.

PELEIAS, I. R. et al. Evolução do Ensino da Contabilidade no Brasil: uma análise histórica. R. Cont. Fin. USP São Paulo. Edição 30 Anos de Doutorado. p.19 - 32. Junho/2007.

QUINTANA, Mabel Maria Sala. Aprendizagem na percepção dos alunos e professores do ensino superior. 2006.

SANTOS, Rosângela Ferreira. O ensino da contabilidade no campus Jane Vanini. Dissertação. 2006.

SILVA, Maria Vilma da. MOURA, Alexandre Costa. SANTOS, Marta Maria Minervino dos. ASSIS, Quitéria Pereira de. SILVA, Regina Lúcia Buarque da. Dificuldades apresentadas por alunos da educação superior na produção de textos da esfera acadêmica. 2012.

SOARES, M. S. A. (Coord.). Educação Superior no Brasil. Porto Alegre. 2002. Disponível em: 〈http://www.iesalc.unesco.org.ve/programas/nacionales/brasil/infnac_br1.pdf >. Acesso em 26 nov. 2015.

STALLIVIERI. Luciane. O sistema de ensino superior do Brasil características, tendências e perspectivas. 2006. 
UNESCO. Qualificação e Capacitação de Professores. Disponível em:

http://www.unesco.org/new/pt/brasilia/education/educational-governance/teacher-educationand-training/. Acesso em 11 dez. 2015. 